Original Research Paper

\title{
Assessment of Current Musher Practices across the Sled Dog Industry with an Emphasis on Nutritional Programs Implemented
}

\author{
James Templeman, Susan Mai, Cara Cargo-Froom and Anna-Kate Shoveller \\ Department of Animal Biosciences, University of Guelph, Guelph Ontario, Canada, N1G 2W1, Canada
}

\author{
Article history \\ Received: 20-09-2017 \\ Revised: $31-10-2017$ \\ Accepted: 5-01-2018 \\ Corresponding Author: \\ Anna-Kate Shoveller \\ Department of Animal \\ Biosciences, University of \\ Guelph, Guelph Ontario, \\ Canada, N1G 2W1, Canada \\ E-mail: ashovell@uoguelph.ca
}

\begin{abstract}
A questionnaire was developed and advertised broadly to the sled dog community to assess current habits and practices in the mushing industry to help guide future research in sporting dogs. The questionnaire covered nutritional programs, housing, training and health and well-being. Sled dog nutrition management is a controversial topic and while there is a dearth of available information on the nutrient requirements of these canine athletes, without adequate data based evidence, nutrition management decisions cannot always be scientifically based. Therefore, this report focused on evaluating nutrition programs used among mushers and differences in feeding management between racing- and off-seasons. Food type provided differed among mushers $(P=0.01)$, with combination diets accounting for $62 \%$ of responses. The source of homemade diet recipes differed $(P<0.0001)$, with $50 \%$ of mushers sourcing their recipes from experienced mushers in contrast to animal nutritionists, $16 \%$; veterinarians, $6 \%$; or journals, $3 \%$. When asked what nutrient(s) respondents felt were important to focus their nutritional programs on, more than $85 \%$ of respondents felt that protein and fat were important nutrients, and less than $40 \%$ believed fiber or carbohydrates to be essential dietary components. Raw meat and oils were the two most commonly supplemented products, and 50\% of respondents report supplementing antioxidants. A majority of respondents provided the same amount of feed and water during racing and off-seasons, even though dogs' nutrient demands and rate of water-turnover increase when increasing athletic activity. This data indicates that nutrition programs are largely tailored towards high protein and fat diet formulations, with little attention to the risks of raw meat supplementation, the appropriate balance of nutrients and structuring nutritional programs to meet seasonal requirements. These results suggest that scientific investigation into the dietary fiber, better balanced proteins and better feeding management are warranted.
\end{abstract}

Keywords: Musher, Nutrition, Sled Dog, Questionnaire

\section{Significant Statement}

A questionnaire was developed and advertised broadly to the sled dog community as a method of assessing the current habits and practices in the mushing industry to help guide future research in sporting dogs. The results suggest that scientific investigation into dietary fiber, antioxidant supplementation, better balanced proteins and improved feeding management are warranted, as well as appropriate knowledge translation to enable the application of nutrition into practice. Additional attention must also be paid to the risks and repercussions of raw meat supplementation which is a common practice in the sled dog industry and has the potential to be detrimental to the health and athletic performance of these sporting dogs.

\section{Introduction}

In the Northern regions of the world, there is evidence of humans using canines (Canis familiaris) to pull sleds spanning back as far as four thousand years (Coppinger, 1979; Hermann and Keith, 1997). The sled 
dog industry has come a long way since then, however, even with the advancements that have been made, much is unclear regarding consistency in the current industry with respect to practices including the training regimes, nutrition programs and the environmental management of these athletic dogs. It is likely that these differences could result in variable health and overall welfare of this unique canine cohort, with much of the variation potentially stemming from the nutritional programs being developed and utilized by the mushers (Cantor et al., 1997; Hill, 1998; Massimoino et al., 2000).

The National Research Council (NRC, 2006) thoroughly outlines the maintenance nutrient requirements (e.g., protein, fat, carbohydrate, vitamins, minerals, and energy demands) for canines of all life-stages; however, asides from recommended metabolizable energy (ME) requirements, there is no detailed description of the specific nutritional requirements for the athletic, performance dogs. A number of mushing organizations (e.g., Mush with P.R.I.D.E, International Sled Dog Racing Association; ISDRA, International Sled Dog Veterinary Medical Association; ISDVMA) have established general guidelines for sled dog management, including suggested nutritional programs to provide information to the industry. For example, Mush with P.R.I.D.E. published a manual titled "Sled Dog Care Guidelines" (3rd ed., 2009, retrieved from: http://www.mushwithpride.org/Guidelines /PDFs/3rd\%20Edition\%20guidelines,\%20edited1.pdf)

that recommends industry standards for the housing, health care, training and nutrition for sled dogs at all lifestages. The nutritional recommendations put forth by these organizations as well as from the sources considered more reputable (e.g., Nutrient Requirements of Dogs and Cats, National Research Council) are all compiled using very few studies that vary in the breeds utilized and environmental conditions. Additionally, very few of the studies cited would be considered recent, with a number dating back to the mid-twentieth century or earlier. The historical scientific literature may not accurately represent the current population of racing dogs as generations of selective breeding has changed the genetics of individual sled dog breeds (Huson et al., 2010; Brown et al., 2015), not to mention the wide variety of breed-to-breed differences in physiology, metabolism, and behaviour (Weber et al., 2002; Hernot et al., 2005; Beckmann et al., 2010; Turcsán et al., 2011). This all collectively contributes to disparity between mushers and researchers/clinicians concerning nutritional programs. Much of the controversy emanates from what the two parties consider to be the adequate dietary requirements for these dogs, as well as issues surrounding the supplementation of raw meat to sled dog diets, which is commonplace in the mushing industry.

Canine athletes require intensively managed nutrition programs due to the unique way in which they metabolize and utilize nutrients (Hill, 1998). Depending on body weight, level of fitness, breed, intensity of exercise, and environmental conditions, sled dogs' maintenance energy requirements can be elevated to upwards of 11,250 kcal ME per day (Hinchcliff et al., 1997; Hill, 1998; Loftus et al., 2014). When this is compared to a minimally active, 50-pound adult dog that typically requires $<1,200 \mathrm{kcal} \mathrm{ME}$ per day to maintain its body weight (Burger, 1994; Waltham, 2017, retrieved from: https://www.waltham.com/document/\%20nutrition $/ \mathrm{dog} / \operatorname{dog}$-nutrient-requirement/286/), it is clear how important it is that these intensively exercised sled dogs have a very focused nutritional program, where they receive a high quality, nutritionally balanced diet.

Feeding raw animal-sourced protein to companion animals is a controversial issue, leading to the American Veterinary Medical Association (AVMA) releasing a policy to prevent the feeding of inadequately treated, raw or undercooked meat in cat and $\operatorname{dog}$ diets (AVMA, 2017, retrieved from: https://www.avma.org/KB/Policies/Pages/Raw-or-Un dercooked-Animal-Source-Protein-in-Cat-and-Dog-D iets.aspx). Amid the controversy, the addition of raw meat to sled dog diets remains common practice (Hill, 1998; Morley et al., 2006). In small quantities, and in a very controlled manner, eating raw meat can be acceptable for humans and animals alike, however mushers are generally purchasing large amounts of inexpensive, low quality raw meat that is likely to be quite variable in terms of nutrient content and at a high risk of bacterial contamination (Cantor et al., 1997; Hill, 1998; Morley et al., 2006; Strohmeyer et al., 2006).

The objectives of this study were to: (a) evaluate the current habits and practices related to the nutritional programs utilized in the sled dog industry using an online questionnaire circulated throughout the mushing community, and (b) to assess differences in food type, water allotment, feeding frequency and food quantity between the racing-season and the off-season. Accomplishing these objectives will allow the identification of areas where controlled research is needed to evaluate potential improvements in canine nutrition, health, welfare and athletic performance. To our knowledge, no published survey to date has focused specifically on contemporary mushing practices and nutritional programs tailored towards this particular athletic canine cohort. The data collected from this study will assist in the need and design of future studies that have the potential to improve the overall health and well-being of sled dogs.

\section{Materials and Methods}

\section{Questionnaire Development}

The questionnaire (Supplementary Table 1) was developed based on the guidelines established by a number of musher-dedicated organizations (e.g. ISDVMA), however an unpublished personal communication by Marcelissen et al. was also referred to when compiling the question bank. Marcelissen and 
company attempted a similar questionnaire-based study over 10 years ago as they looked to assess the current state of sled dog care in North America.

The questionnaire for this study consisted of 80 questions subdivided into six sections: (1) owners' background information and demographics, 8 questions; (2) housing management, 12 questions; (3) nutritional programs, 24 questions; (4) training regimes, 26 questions; (5) dog health and wellbeing, 3 questions; and (6) owners' overall knowledge of mushing practices, 6 questions. The first question of the study was the consent agreement, for which the respondent had to agree to continue on to the proceeding 79 questions.

\section{Subjects and Survey Circulation}

Musher recruitment began on March $7^{\text {th }}, 2017$ and the questionnaire was open and active for a two-week period before it was closed on March $21^{\text {st }}$ for data collection. Throughout the initial collection period, the survey accumulated 72 total respondents. Access to the questionnaire was advertised by means of a contact list that was created from publically accessible musher forums, as well as through social media accessed sled dog groups (e.g., Mushing Tips Worldwide). Participants gained access to the questionnaire anonymously via a secure link provided within the advertised postings.

Access required the participant to be 18 years of age or older and was limited to a single questionnaire per participant. A consent form provided participants with background information outlining the researchers involved, the purpose of the questionnaire, the expected time to complete the survey, the inclusion criteria for participation, and a description of how the data would ultimately be utilized. The participants had the right to withdraw from the study at any time and could request to have their data removed from the study. At no time did the survey ever request participants to provide personal information. The study was approved by the University of Guelph and Research Ethics Board (REB \#17-02-017, March $\left.7^{\text {th }}, 2017\right)$.

\section{Statistical Analysis}

Descriptive statistics for each survey question provided were initially reported as number of respondents per question, as well as the actual counts and percentage of responses for each answer (within each question). All data was then analyzed using SAS software (SAS Inst. Cary, NC; version 9.4). Each question was analyzed with the PROC FREQ command using Test P. A Chi ${ }^{2}$ test was used to compare the predicted values to the actual values, where predicted values were considered equal across all available options. Significance was declared at $P<0.05$.

\section{Results}

The results presented are based on data collected from all 72 respondents. There is variation for the total number of responses for each question due to the fact that some questions may not have been applicable to all respondents (for example, see Q2 proceeded by Q4, Supplementary Table 1). Unfortunately, due to the lack of responses for the questions concerning housing practices, questions 1021 (Supplementary Table 1) were removed from analysis. This drop off in response numbers was assumed to be potentially due to recent controversies regarding sled dog housing practices circulating popular media around the time this survey was released.

\section{Musher Demographics}

Forty-four percent of respondents reported that they breed sled dogs for racing purposes (NS; Q1, Table 1), and of those who breed, a majority have been breeding and racing sled dogs for ten years or more $(67 \%$; Q2, Table 1). Respondents reported that they participate in mainly sprint races $(47 \%$; Q3, Table 1), with the remaining respondents taking part in distance (endurance) races, less conventional races (e.g., stage top or skijoring), or a combination of racing styles. Seventyfour percent of respondents own between 1 and $20 \mathrm{dogs}$, with only $3 \%$ owning more than 50 (Q4, Table 1). Of those dogs owned, a majority of the respondents reported to race or breed more Alaskan Huskies than any other dog breed (54\%; Q5, Table 1). Siberian Huskies (34\%) and Euro-hounds (22\%) accounted for a bulk of the remaining selections, with "other" breeds (e.g., Border Collies, Labrador Retrievers) making up the remaining $12 \%$.

\section{Nutrition Program Fundamentals}

The type of diet fed differed between mushers $(P=$ 0.0139; Q6, Table 2), with 62\% feeding a combination diet. This diet type combines a commercial brands' nutritionally complete and balanced diet with a "homemade ration" of an undisclosed nutrient balance. A majority of respondents stated they made homemade rations based on recipes handed down from experienced mushers $(50 \%)$, with only $25 \%$ of respondents using data based scientific consults to formulate their homemade rations (animal nutritionists, $16 \%$; veterinarians, $6 \%$; peer-reviewed journals, $3 \%$; Q7, Table 2). In terms of the commercial brands of food chosen (Q8, Table 2), the most common selection was Redpaw dog food (Redpaw Inc., Franklin, WI) accounting for $25 \%$ of responses, followed by Inuksuk (13\%; Corey Nutrition Company, Fredericton, NB) and Caribou Creek Gold (12\%; Caribou Creek, Chatham, MI). The "other" food brands that made up the remaining 50\% included Annamaet (Annamaet Petfoods, Sellersville, PA), Orijen (Champion Petfoods, Morinville, AB), Royal Canin (Royal Canin Canada, Puslinch, ON), and others.

The dietary nutrient(s) respondents felt were important to focus their nutritional programs on differed among respondents $(P<0.0001$; Q9, Table 2). More than $85 \%$ of respondents believed protein and fat to be important nutrients, and $<40 \%$ saw fiber or carbohydrates as significant dietary nutrients. 
Table 1: Musher demographics pertaining to whether or not the respondents breed and/or race, the types of races they take part in, and how many dogs they own

\begin{tabular}{|c|c|c|c|}
\hline Question & Frequency & $\mathrm{Chi}^{2}$ & $P$-value \\
\hline \multicolumn{4}{|c|}{ Q1. Do you breed dogs for racing? $(n=68)$} \\
\hline A. Yes & 44.12 & 1.38 & NS \\
\hline B. No & 55.88 & & \\
\hline \multicolumn{4}{|c|}{ Q2. How long have you been both breeding and racing dogs? $(\mathrm{n}=30)$} \\
\hline A. $0-1$ years & 0.00 & 52.68 & $<0.0001$ \\
\hline B. $1-5$ years & 10.00 & & \\
\hline C. $5-10$ years & 23.33 & & \\
\hline D. $10+$ years & 66.67 & & \\
\hline \multicolumn{4}{|c|}{ Q3. Type of races you compete in? $(n=64)$} \\
\hline A. Sprint & 46.88 & 32.23 & $<0.0001$ \\
\hline B. Distance & 28.13 & & \\
\hline C. Other & 10.94 & & \\
\hline D. More than one & 14.06 & & \\
\hline \multicolumn{4}{|c|}{ Q4. How many dogs do you own? $(\mathrm{n}=65)$} \\
\hline A. $1-20$ & 73.85 & 79.85 & $<0.0001$ \\
\hline B. $21-50$ & 23.08 & & \\
\hline C. $50+$ & 3.08 & & \\
\hline \multicolumn{4}{|c|}{ Q5. What type of breeds do you use for breeding or racing? $(n=67)$} \\
\hline A. Alaska Huskies & 52.24 & 29.67 & $<0.0001$ \\
\hline B. Euro-hounds/ Pointer cross & 22.39 & & \\
\hline C Siberian & 34.33 & & \\
\hline D. Other & 11.94 & & \\
\hline
\end{tabular}

Significance declared at $P<0.05$. NS; Not Significant

Table 2: Respondent reports regarding the types of diets most commonly fed, the common commercial brands of dog food used, the sources of homemade recipes, and the importance of individual nutrients

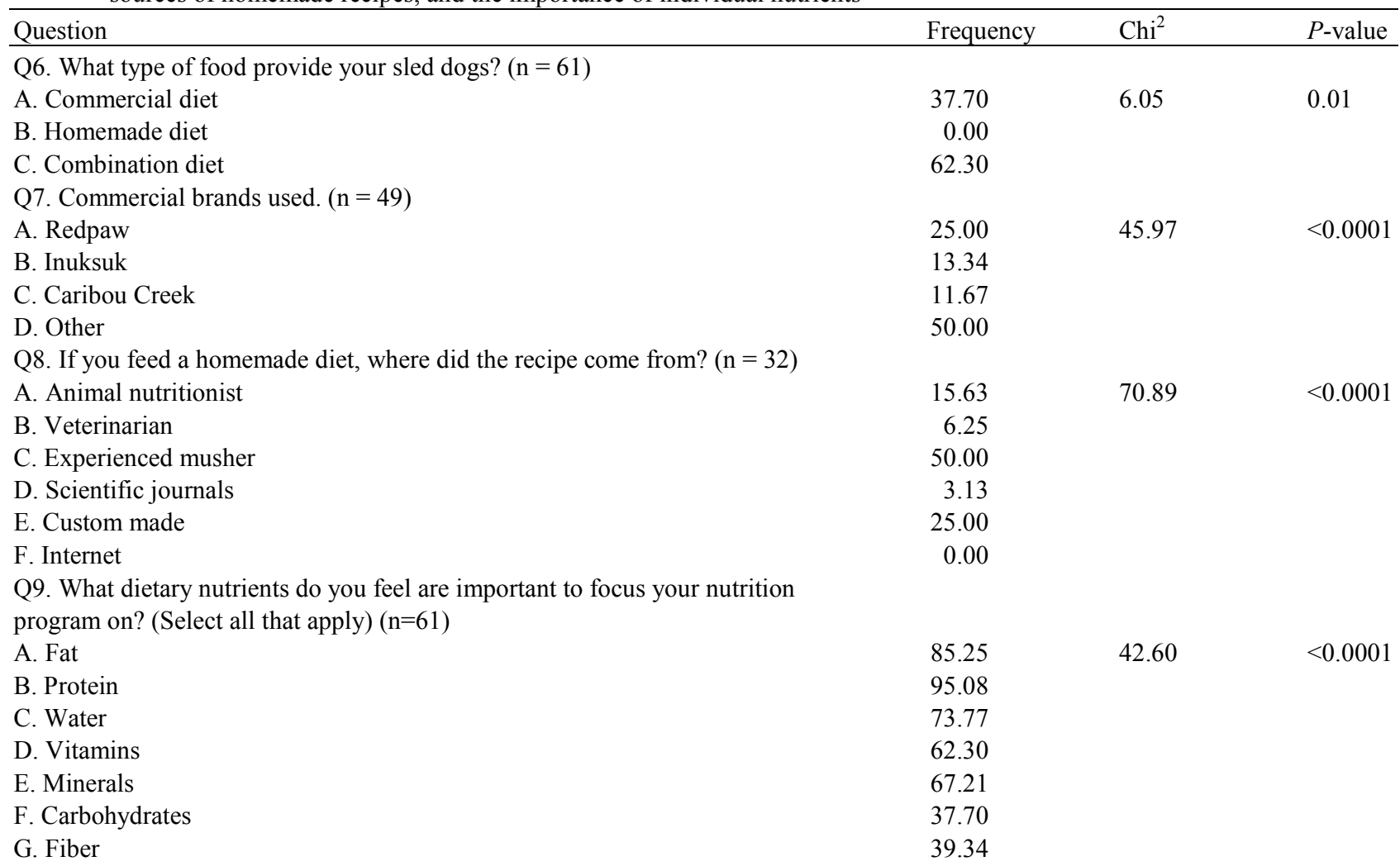

Significance declared at $P<0.05$ 


\section{Dietary Supplementation}

A significant portion of respondents reported that they incorporate dietary supplements into their dogs' diets $(P<0.0001)$, however of those who do provide supplements, only $50 \%$ include dietary antioxidant sources into their supplementation formula (Q10/12, Table 3). When asked to list the supplements they incorporate into their dogs' diets, raw meat (59\%), animal or plant based oils (46\%), vitamins and minerals $(36 \%)$, and psyllium husks $(27 \%)$ were most commonly reported by the mushers (Q11, Table 3). There was also a wide variety of "other" supplements mushers reported using including pumpkin, kelp, licorice root, brewer's yeast, apple cider vinegar, and a number of other less common supplements. Of those who reported to include antioxidant sources as a portion of their supplementation, Vitamins E (63\%) and C (31\%) as well as astaxanthin $(19 \%)$ accounted for a bulk of the responses (Q13, Table

3). Eight individuals reported "other" antioxidant sources, $50 \%$ of which are not categorized as antioxidants (e.g., FortiFlora ${ }^{\circledR}$ probiotic supplement, Purina Canada, Mississauga, ON).

\section{Seasonal Variation in Nutrition Programs}

The type of diet being fed differed in both the off- and racing-seasons $(P<0.0001)$. The combination diet was the most commonly chosen diet type in both seasons, however it was fed 1.9 times more frequently during the racingseason compared to the off-season (Fig. 1).

In regards to feeding frequency, a majority of mushers feed their dogs the same amount of times per day, no matter the season (59\% off-season, 64\% racing-season; Fig. 2). When asked how much (volume basis) they feed each dog, per day, the most commonly chosen answer during both the off-season (56\%) and racing-season (38\%) was 1-2 cups (Fig. 3). Approximately $30 \%$ of mushers claimed that they "didn't know" how much food they were providing to each dog, regardless of what season it was (Fig. 3).

Table 3: Overview of dietary supplementation, types of supplements provided, and antioxidant provision

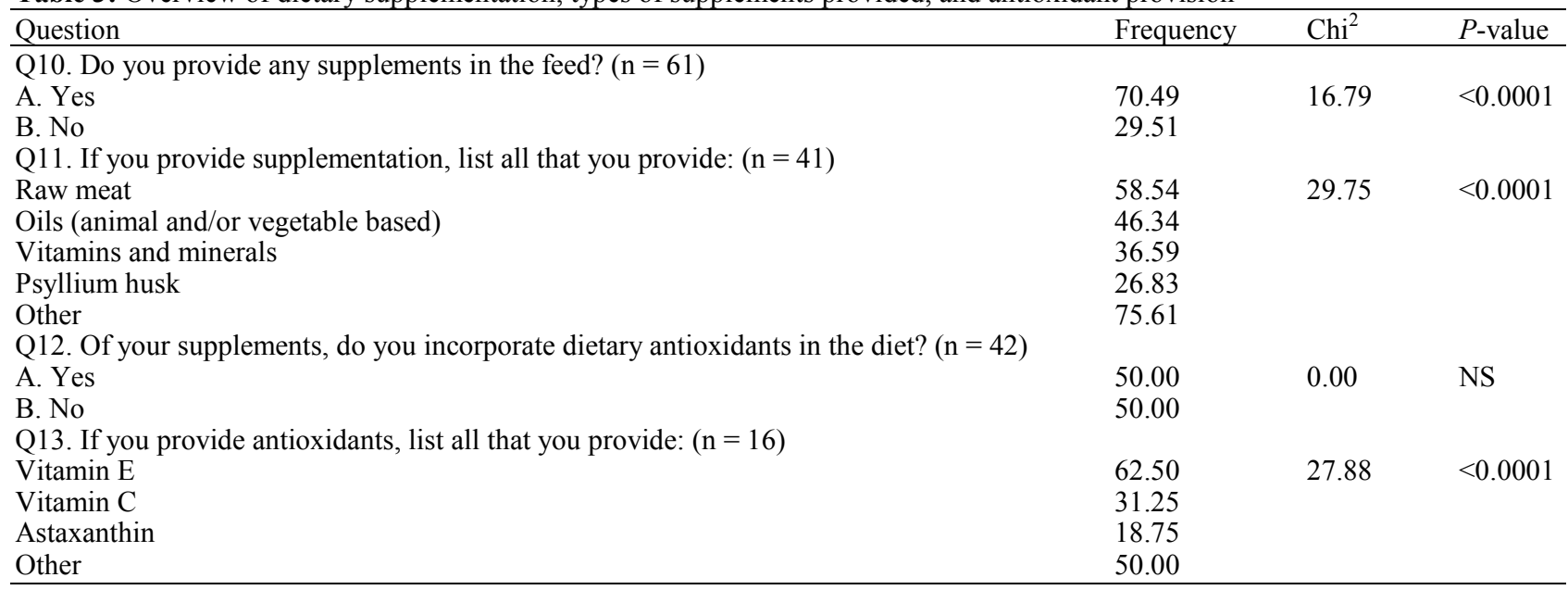

Significance declared at $P<0.05$. NS; Not Significant

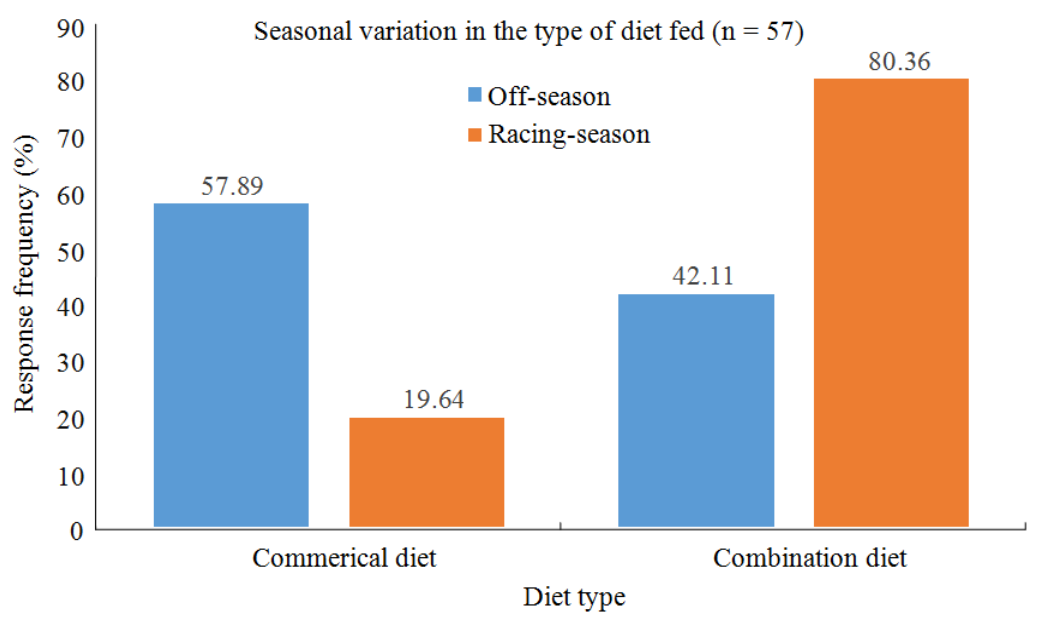

Fig. 1: Comparison of diet type fed (commercial diet or combination diet) by the respondents during the off-season versus the racingseason 


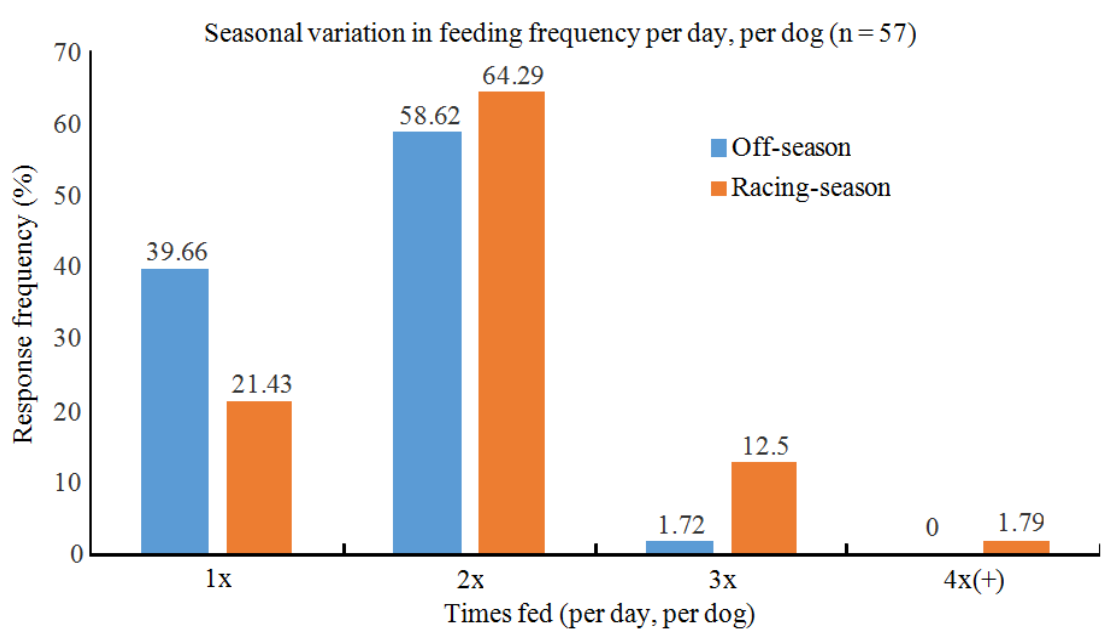

Fig. 2: Comparison of how frequently respondents report to feed their dogs $(1,2,3$, or $4+$ times fed per day, per dog) during the offseason versus the racing-season

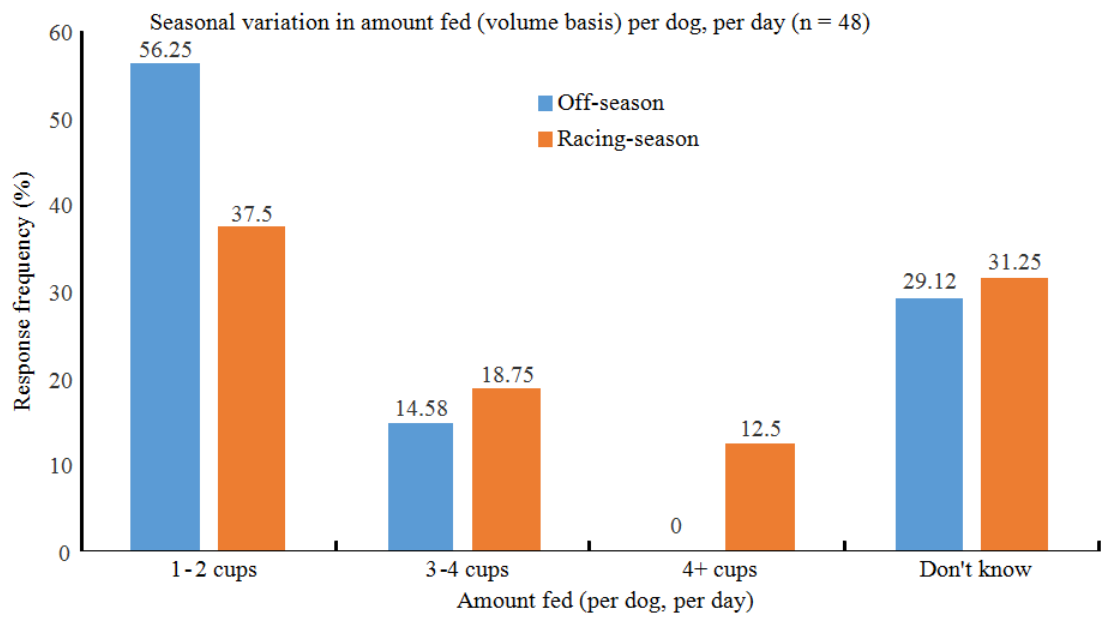

Fig. 3: Comparison of the amount of food, on a volume basis, that respondents report to feed their dogs (per dog, per day) during the off-season versus the racing-season

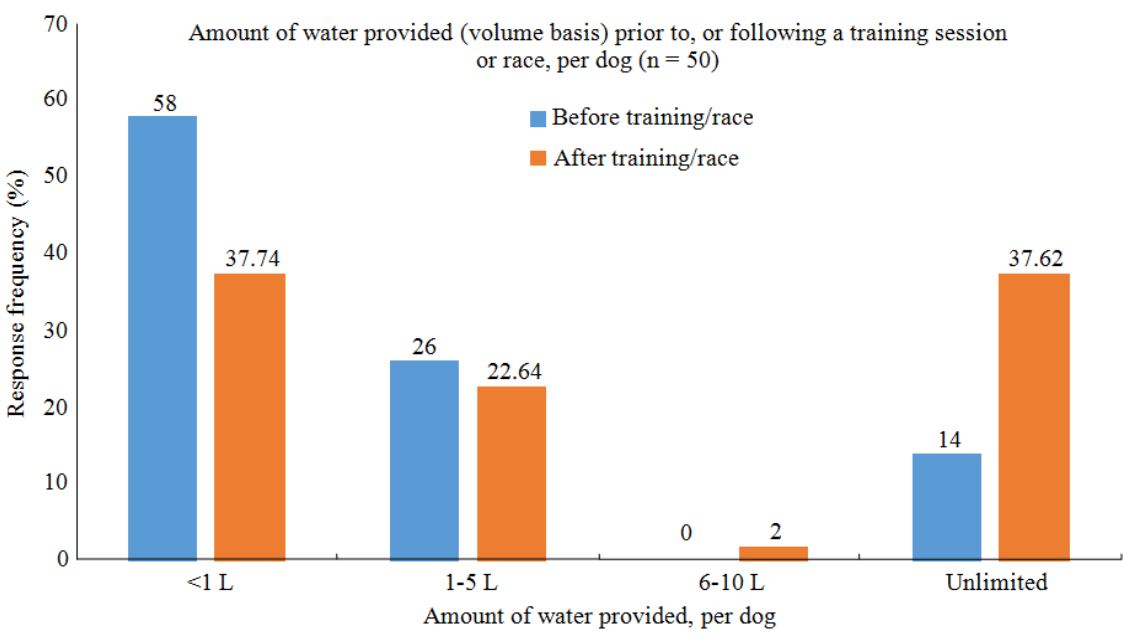

Fig. 4: Comparison of how much water, on a volume basis, that respondents report to provide their dogs (per dog, per day) during the off-season versus the racing-season 
During the racing-season, a significant portion of mushers reported to monitor the water intake of their dogs $(89 \% ; P<0.0001$, data not shown). Of those who do monitor intake, $50 \%$ only provide between 1-5 L of water (per dog, per day), and a lesser percentage of mushers provide unlimited water during the racing season than during the off-season (Fig. 4).

A significant amount of mushers offer water to their dogs prior to a training session or race $(96 \% ; P<0.0001$, data not shown). However, among those who provide pretraining/race water, $58 \%$ provide less than $1 \mathrm{~L}$ of water and $26 \%$ provided between 1-5 L (data not shown).

\section{Discussion}

Upon assessing the current nutrition-related habits and practices of the 72 respondents, we observed that mushers are over-indexing on the use of homemade diets and supplementation of raw meat while under appreciating the importance of fiber. With regards to nutritional management, it appears as though the respondents are not appropriately adjusting dietary intake levels to maintain the dogs' optimum body condition.

The respondents predictably owned more Alaskan Huskies than any other breed as mushers have been moving away from the earliest lineages of sled dog breeds such as Siberian Huskies, Samoyeds, Alaskan Malamutes and Canadian Eskimo Dogs (Qimmits). The Alaskan Husky, a quicker, longer-legged cousin of the Malamute and Siberian is the product of a century of cross-breeding (crossed with Shepherds or Greyhounds) and careful selection aimed at maximizing the athletic potential of this breed (Brown et al., 2015). Alaskans Huskies and "sprint Huskies", or Eurohounds (Alaskan and Pointer cross), have gained popularity as the mushing community proceeds away from the traditional long distance, endurance races and progressed into today's largest sled dog racing venture of sprint racing (Huson et al., 2010). This trend towards short, high intensity sprintstyle races is evident with the reports collected from this study relating to both choice of racing style and breed of dog raced or bred (Q3/5, Table 1).

\section{Nutrition Program Fundamentals}

The brands most commonly reported to be fed target mushers specifically by catering their diet formulations directly towards high energy working dogs. Depending on the environmental conditions, as well as the length and intensity of exercise, sled dogs can require upwards of 8 times the maintenance ME requirements of other adult, medium sized dog breeds (Hinchcliff et al., 1997; Hill, 1998; NRC, 2006). To meet this elevated energy demand, commercial brands that formulate their diets for performance dogs do so by elevating the inclusion levels of protein and fat. These diets aim to have $>30$ and
$>50 \%$ of the total energy provided by protein and fat, respectively, thus meeting or exceeding a 30:20 ratio of protein to fat on a content basis (Hill, 1998). However, a majority of respondents report feeding combination diets where the commercial brand food is combined with a self-mixed ration, largely consisting of meat-based feeds. Mushers utilize this diet type as they can increase the energy density, water-content, palatability and digestibility of the diet (Cantor et al., 1997), with these features likely contributing to the use of this diet type increasing by nearly one-fold during racing-season as opposed to the off-season (Fig. 1). However, without procuring help from data-based research consultation sources, such as animal nutritionists (such sources only accounted for $25 \%$ of responses; Q8, Table 2), these homemade rations can have an improper balance of macro and micronutrients that could deleteriously affect health, longevity and performance.

As is, the animal based protein sources that contribute significantly, or even exclusively to the homemade rations are not nutritionally balanced and the nutrient content can vary greatly from source to source due to the variety of feed stuffs the animals consume prior to slaughter and the variation in the tissues included. Muscle meat alone is not nutritionally complete and must be fed along with other animal based sources (e.g. skin or organ meat) in order for the dogs to receive a more complete collection of nutrients (USDA Food Composition Databases, 2016, retrieved from: https://ndb.nal.usda.gov/ndb/). However, even by combining the nutrient profiles of these animal products, other sources of supplementation may still be necessary in order to meet certain nutrient requirements (e.g. appropriate calcium to phosphorus ratio). Thus, if inadequately formulated, meat-based rations can pose potential risks via nutritional deficiencies (e.g. calcium deficiency: poor bone mineralization, hyperparathyroidism) or excessive inclusion (e.g. iron or vitamin A toxicity with disproportionate intake of animal liver) (Hill, 1998). These issues can be exacerbated if this homemade ration is also not balanced appropriately with the nutritionally complete commercial food, or if nutrients already present in the commercial food (especially micro minerals) are not accurately accounted for (Hill, 1998).

These homemade rations also introduce another, more thoroughly studied complication and potential risk to the dogs' health: bacterial contamination from raw meat. The traditional and yet enduring practice of feeding raw meat to sled dogs (Cantor et al., 1997) likely stems from the precedence paid to high protein and high fat diets for performance dogs (discernible in the responses to Q9, Table 2 and Q11, Table 3). Whether it has been sold for human consumption or, alternatively, recognized as unfit for human use, raw meat poses a risk of bacterial contamination (LeJeune and Hancock, 2001; 
Weese et al., 2005; Strohmeyer et al., 2006; reviewed by Freeman et al., 2013) and due to cost considerations surrounding protein sources, lower cost and lower quality meat products are being more frequently utilized for feeding (Morley et al., 2006). A number of studies have outlined the risks of bacterial contamination when feeding raw meat-based diets and described the pathogenic microorganisms with the highest likelihood of negatively impacting the dogs being fed. Strohmeyer et al. (2006) isolated Salmonella enterica and Escherichia coli (E. coli) in at least one sample for each of the four different raw meat diets tested, with $E$. coli being recovered $60 \%$ of the 240 samples. Similarly, Weese et al. (2005) isolated E. coli and Salmonella spp. in 64 and $20 \%$ of 25 different commercial raw cat and dog diets, respectively, while also detecting Clostridium perfringens (C. perfringens) (20\%) and enterotoxigenic Staphylococcus aureus (S. aureus) (4\%). With racing greyhound dogs, an industry where feeding raw meat is as common as it is in the mushing community, Salmonella spp. were detected in $45 \%$ of meat samples tested by Chengappa et al. (1993) and in 66\% of the 133 raw meat samples analyzed by Morley et al. (2006).

Dogs can be susceptible to both bacterial infection (caused by ingesting a food with live bacteria) and bacterial intoxication (caused by ingesting a food containing toxins produced via bacterial growth). There are reports of $C$. perfringens- and Salmonella-related gastroenteritis in dogs, as well as enteric-related illnesses linked the toxin-producing $S$. aureus (LeJeune and Hancock, 2001). These issues can compromise immune function and hamper the athletic performance of these racing dogs in a similar fashion to what has been seen in exercising humans. Decreased aerobic exercise capacity and decreased isotonic muscle strength have been observed in humans with a compromised immune system (e.g. viral infection) compared to baseline measurements taken when healthy (Friman and Wesslén, 2008). Furthermore, as these bacterial species are typically shed in the feces, the risk of spreading the contamination to other dogs housed nearby is high, as is the risk of zoonotic transfer to the human handlers (depending on the bacterial strain). For sled dogs at 1996 Iditarod race, Salmonela spp. were found in $69 \%$ of fecal samples prior to the race and $60 \%$ of fecal samples taken during the race (Cantor et al., 1997).

With only $39 \%$ of respondents reporting fiber as significant nutrient for their dogs' nutritional programs (Q9, Table 2), more must be done to improve and widen breadth of public knowledge regarding the importance of fiber to canine gut and for whole body health. While dogs do not depend on microbial fermentation of fiber for the provision of energy, the volatile fatty acids produced via soluble fiber fermentation promote the colonic absorption of water and electrolytes and, largely on account of butyrate, can work to prevent colonic motility dysfunction (e.g. constipation or diarrhea) (Velázquez et al., 1997; Hill, 1998). Dietary soluble fiber will also improve a performance working dogs' fecal scores, evacuation efficiency, and ability to control defecations under stressful conditions (Coffman, 2000). As well, fiber plays a vital part in the maintenance of a stable intestinal microbial population, in turn preventing intestinal diseases associated with drastic changes to the microbial environment (Swanson et al., 2011).

\section{Dietary Supplementation}

During high energy aerobic exercise, the combination of increased oxygen consumption and an elevated metabolic rate results in sled dogs having increased lipid peroxidation, thus increasing free radical production (Piercy et al., 2001; Reinhart and Altom, 2002; Hinchcliff et al., 2003). The elevated free radical production that occurs with the combination of endurance exercise and aerobic metabolism of high fat diets may contribute to exercise-induced muscle damage in these performance dogs (Hinchcliff et al., 2000; Hinchcliff et al., 2003). While a majority of respondents in this study claim to incorporate supplements into their dogs' diets, the two most commonly supplemented items (raw meat [59\%] and oils [46\%]; Q11, Table 3) will both increase fat content of the diet, thus increasing the risk of oxidative stress via lipid peroxidation.

Antioxidant imbalance and the resulting oxidative stress is also believed to be a contributing factor for issues related to impaired gastrointestinal function, such as increased gastric permeability and gastritis (Ulutas et al., 2006; Hashimoto et al., 2008). According to the necropsy findings of the 23 sled dogs reported to have died at the Iditarod between 1994 and 2006, the most common lesions detected included gastritis $(\mathrm{n}=10)$, enteritis $(\mathrm{n}=$ $10)$, and gastric ulceration $(n=10)$, with of 12 of the 23 deaths related to gastrointestinal disease (Dennis et al., 2008 ). Only $50 \%$ of respondents in this study report to supplement dietary antioxidant sources (Q12, Table 3), and 8 of the 16 respondents listed "antioxidant sources" that have no antioxidant action at all (e.g. probiotics or fish oils). Given the lack of understanding around the role of antioxidants in performance dog nutrition, further research is warranted and appropriate knowledge translation is necessary to enable the application of nutrition in practice.

\section{Seasonal Variation in Nutrition Programs}

Nutritional mismanagement when transitioning from the off-season to the racing-season can be detrimental to the fitness, stamina, and exercise capacity of these preformance dogs. Nutrient and energy proportions must be adjusted appropriately to meet the requirements of each dog, whether seasonal or daily requirements. 
However, a majority of respondents are not adjusting feeding frequency (feeding 2x per day; Fig. 3) or feed intake (feeding 1-2 cups; Fig. 2) to match their dogs' seasonal energy demands. To maintain a dog's health while optimizing athletic performance, large changes in body weight should be avoided, as both weight gain (e.g. over-feeding in the off-season) and weight loss (e.g. under-feeding in the racing-season) can be detrimental. Energy balance should be sustained by attempting to match a dog's energy intake to their energy utilization while avoiding overly positive or negative energy balances which lead to fluctuations in body weight (Reinhart and Altom, 2002). This energy balance can only be managed if intake levels are closely monitored. Monitoring intake will also allow owners to detect early signs of illness, as many ailments will result in signs anorexia (Delaney, 2006) or, in some cases, polyphagia (Peterson et al., 1981).

In regards to hydration, these athletic dogs turn over water at a higher rate than the average canine (Hill, 1998) and even though exercise reduces the gastric emptying rate of liquids, this turnover rate increases by upwards of 5 times when racing as compared to being kenneled (Hinchcliff and Reinhart, 1996). To sustain proper metabolism and maintain an appropriate internal temperature, sled dogs can turn over an average of $5 \mathrm{~L}$ of water per day when racing (Hill, 1998). According to the responses, during the racing season $50 \%$ of respondents are providing between 1 and $5 \mathrm{~L}$ per day, however the questionnaire did not yield data pertaining to where in that 1-5 L range respondents fell (Fig. 4). As well, the data only reports how much water was provided, not how much water was consumed.

\section{Conclusion}

This survey offers opportunities to focus on both research and knowledge transfer to the sled dog community through potential improvements in nutrition, well-being and athletic performance. To accomplish these goals, consideration must be given to: (a) the importance of using scientific/clinical consultation when formulating a homemade ration; (b) the risks and repercussions of raw meat supplementation; (c) the purpose and benefits of antioxidant supplementation; (d) the nutritional need for fiber to maximize gut health; and (e) nutritional programs suitably structured to meet seasonal requirements.

\section{Acknowledgement}

The authors are grateful for the financial support provided by Dr. Anna-Kate Shoveller's startup funding from the University of Guelph.

\section{Author's Contributions}

James Templeman: Designed and advertised the survey, analyzed the data, drafted and revised the manuscript. Gave final approval of the version to be submitted.

Susan Mai: Designed and advertised the survey, analyzed the data, assisted in drafting the article. Gave final approval of the version to be submitted.

Cara Cargo-Froom: Analyzed and interpreted the data, revised and edited the manuscript. Gave final approval of the version to be submitted.

Anna-Kate Shoveller: Designed and advertised the survey and revised the manuscript critically for important intellectual content. Gave final approval of the version to be submitted.

\section{Conflict of Interest}

The authors declare no conflict of interest.

\section{Ethics}

This article is original and contains unpublished material. The corresponding author confirms that all of the other authors have read and approved the manuscript and no ethical issues involved.

\section{References}

Beckmann, M., D. Enot, D. Overy, I.M. Scott and P.G. Jones et al., 2010. Metabolite fingerprinting of urine suggests breed-specific dietary metabolism differences in domestic dogs. Br. J. Nutr., 103: 1127-1138. DOI: 10.1017/S000711450999300X

Brown, S.K., C.M. Darwent, E.J. Wictum and B.N. Sacks, 2015. Using multiple markers to elucidate the ancient, historical and modern relationships among North American Arctic dog breeds. Heredity (Edinb.), 115: 488-495. DOI: 10.1038/hdy.2015.49

Burger, I.H., 1994. Energy needs of companion animals: Matching food intakes to requirements throughout the life cycle. J. Nutr., 124: 2584S-2593S. PMID: 7996245

Cantor, G.H., S. Nelson, J.A. Vanek, J.F. Evermann and I.S. Eriks et al., 1997. Salmonella shedding in racing sled dogs. J. Vet. Diagn. Invest., 9: 447-448. DOI: $10.1177 / 104063879700900424$

Chengappa, M.M., J. Staats, N.H. Oberest, N.H. Gabbert and S. McVey, 1993. Prevalence of Salmonella in raw meat used in diets of racing Greyhounds. J. Vet. Diagn. Invest., 5: 372-377. DOI: $10.1177 / 104063879300500312$

Coffman, M., 2000. Conditioning the Performance Dog. In: Nutrition for Competitive Dogs. The Iams Company, Dayton, OH, USA, pp: 6-11. 
Coppinger, L., 1979. The World of Sled Dogs: From Siberia to Sport Racing. 1st Edn., Howell Book House: New York, USA, ISBN-10: 0876056710.

Delaney, S.J., 2006. Management of anorexia in dogs and cats. Vet Clin.: Small Anim. Pract. 36: 1243-1249. DOI: $10.1016 /$ j.cvsm.2006.08.001

Dennis, M.M., S.N. Nelson, G.H. Cantor, D.A. Mosier and J.E. Blake et al., 2008. Assessment of necropsy findings in sled dogs that died during Iditarod Trail sled dog races: 23 cases (1994-2006). J. Am. Vet. Med. Assoc., 232: 564-573.

DOI: $10.2460 /$ javma.232.4.564

Freeman, L.M., M.J. Chandler, B.A. Hamper and L.P. Weeth, 2013. Current knowledge about the risks and benefits of raw meat-based diets for dogs and cats. J. Am. Vet. Med. Assoc., 243: 1549-1558. DOI: $10.2460 /$ javma.243.11.1549

Friman, G. and L. Wesslén, 2008. Special feature for the Olympics: Effects of exercise on the immune system: Infections and exercise in high-performance athletes. Immunol. Cell Biol., 78: 510-522. DOI: $10.1111 /$ j.1440-1711.2000.t01-12-.x

Hermann, M. and K. Keith, 1997. An economic discussion of competitive dog mushing. University of Alaska.

Hernot, D.C., V.C. Biourge, L.J Martin, H.J. Dumon and P.G. Nguyen, 2005. Relationship between total transit time and faecal quality in adult dogs differing in body size. J. Anim. Physiol. Anim. Nutr., 89: 189-193. DOI: 10.1111/j.1439-0396.2005.00544.x

Huson, H.J., H.G. Parker, J. Runstadler and E.A. Ostrander, 2010. A genetic dissection of breed composition and performance enhancement in the Alaskan sled dog. BMC Genet., 11: 71-71. DOI: $10.1186 / 1471-2156-11-71$

Hashimoto, K., T. Oshima, T. Tomita, Y. Kim and T. Matsumoto et al., 2008. Oxidative stress induces gastric epithelial permeability through claudin-3. Biochem. Biophys. Res. Comm., 7: 154-157. DOI: $10.1016 /$ j.bbrc.2008.08.140

Hill, R.C., 1998. The nutritional requirements of exercising dogs. J. Nutr., 128: 2686S-2690S. PMID: 9868242

Hinchcliff, K.W. and G.A. Reinhart, 1996. Energy metabolism and water turnover in Alaskan sled dogs during running. Proceedings of the Iams International Nutritional Symposium on Recent Advances in Canine and Feline Nutritional Research, (FNR' 96), Orange Frazer Press, Wilmington Ohio, pp: 199-206.

Hinchcliff, K.W., G.A. Reinhart, J.R. Burr, C.J. Schreier and R.A. Swenson, 1997. Metabolizable energy intake and sustained energy expenditure of Alaskan sled dogs during heavy exertion in the cold. Am. J. Vet. Res., 58: 1457-1462. PMID: 9401699
Hinchcliff, K.W., G.A. Reinhart, R. DiSilvestro, A. Reynolds and A. Blostein-Fujii et al., 2000. Oxidant stress in sled dogs subjected to repetitive endurance exercise. Am. J. Vet. Res., 61: 512-517. PMID: 10803645

Hinchcliff, K.W., P.D. Constable and R.A. DiSilvestro, 2003. Muscle injury and antioxidant status in sled dogs competing in a long-distance sled dog race. Equine Comp. Exerc. Phsyiol., 1: 81-85. DOI: 10.1079/ECEP200311

LeJeune, J.T. and D.D. Hancock, 2001. Public health concerns associated with feeding raw meat diets to dogs. J. Am. Vet. Med. Assoc., 219: 1222-1225. PMID: 11697364

Loftus, J.P., M. Yazwinski, J.G. Milizio and J.J. Wakshlag, 2014. Energy requirements for racing endurance sled dogs. J. Nutr. Sci., 3: e34-e34. DOI: $10.1017 /$ jns.2014.31

Massimoino, S.P., M.G. Hayek and M.A. Ceddia, 2000. Nutrition and the Immune System of Sporting Dogs. In: Nutrition and Care of the Sporting Dog, The Iams Company, Dayton, OH, USA, pp: 23-129.

Morley, P.S., R.A. Strohmeyer, J.D. Tankson and P.J. Fedorka-Cray, 2006. Evaluation of the association between feeding raw meat and Salmonella enterica infections at a Greyhound breeding facility. J. Am. Vet. Med. Assoc., 228: 1525-1532. DOI: $10.2460 /$ javma.228.10.1524

NRC, 2006. Nutrient Requirements of Dogs and Cats. National Academies Press, Washington, DC, USA.

Peterson, M.E., G.H. Nesbitt and M. Schaer, 1981. Diagnosis and management of concurrent diabetes mellitus and hyperadrenocorticism in thirty dogs. J. Am. Vet. Med. Accos., 178: 66-69. PMID: 7009530

Piercy, R.J., K.W. Hinchcliff, P.S. Morley, R.A. DiSilvestro and G.A. Reinhardt et al., 2001. Vitamin $\mathrm{E}$ and exertional rhabdomyolysis during endurance sled dog racing. Neuromusc. Disord., 11: 278-286. DOI: 10.1016/S0960-8966(00)00199-1

Reinhart, G.A. and E.K. Altom, 2002. Feeding for Endurance and Performance of Sporting Dogs. In: Nutrition and Care of the Sporting Dog, The Iams Company, Dayton, OH, USA, pp: 31-38.

Strohmeyer, R.A., P.S. Morley, R.D. Hyatt, D.A. Dargatz and A.V. Scorza et al., 2006. Evaluation of bacterial and protozoal contamination of commercially available raw meat diets for dogs. J. Am. Vet. Med. Assoc., 228: 537-542.

DOI: $10.2460 /$ javma.228.4.537

Swanson, K.S., S.E. Dowd, J.S. Suchodolski, I.S. Middelbos and B.M. Vester et al., 2011. Phylogenetic and gene-centric metagenomics of the canine intestinal microbiome reveals similarities with humans and mice. Int. Soc. Microb. Ecol. J., 5: 639-649. DOI: 10.1038/ismej.2010.162 
Turcsán, B., E. Kubinyi and Á. Miklósi, 2011. Trainability and boldness traits differ between dog breed clusters based on conventional breed categories and genetic relatedness. Applied Anim. Behav. Sci., 132: 61-70. DOI: 10.1016/j.applanim.2011.03.006

Ulutas, P.A., G. Bayramli, B. Ulutas, F. Kiral and A, Atasoy, 2006. Oxidative stress and non-enzymatic antioxidant status in dogs with aspirin induced gastric mucosal injury. Rev. Med. Vet., 157: 401-404.

Velázquez, O.C., H.M. Lederer and J.L. Rombeau, 1997. Butyrate and the colonocyte. Production, absorption, metabolism and therapeutic implications. Adv. Exp. Med. Biol., 427: 123-134. PMID: 9361838
Weber, M.P., L.J. Martin, H.J., Dumon, V.C. Biourge and P.G. Nguyen, 2002. Influence of age and body size on intestinal permeability and absorption in healthy dogs. Am. J. Vet. Res., 63: 1323-1328. DOI: 10.2460/ajvr.2002.63.1323

Weese, J.S., J. Rousseau and L. Arroyo, 2005. Bacteriological evaluation of commercial canine and feline raw diets. Can. Vet. J., 46: 513-516.

PMID: 16048011 